\title{
Americanismo e a Fabricação do "Homem Novo": Circulação e Apropriação de Modelos Culturais na Revista Educação Physica (1932-1945)
}

\author{
Omar Schneider* \\ Amarílio Ferreira Neto**
}

\begin{abstract}
Resumo: Procura explorar a hipótese de que a cultura esportiva veiculada por meio da revista Educação Physica fazia parte de um movimento mais geral de difusão da cultura Norte-Americana sobre a América Latina. Trabalhar com essa hipótese implica examinar, muito detidamente, o padrão cultural vulgarizado pela revista Educação Physica, como resultado de apropriações e assimilações de outros padrões culturais em disputa pela construção de um modelo modernizador capaz de fomentar a produção de um "homem novo" preparado para enfrentar as contingências das transformações sociais, políticas e econômicas que as décadas de 1930 e 1940 concretizaram.
\end{abstract}

Palavras-chave: Revista Educação Physica. Antropologia cultural. Características culturais. Estados Unidos.

\section{INTRODUÇÃO}

O estudo é parte de uma investigação maior que analisou as estratégias editoriais e as prescrições educacionais presentes no periódico intitulado Educação Physica. ${ }^{1} \mathrm{O}$ impresso foi produzido no Rio de Janeiro, pela Companhia Brasil Editora, entre os anos de 1932 e 1945, tendo veiculados 88 números. Ele não teve seus limites

\footnotetext{
* Doutor em Educação. Professor do Departamento de Educação Física da Universidade Federal de Sergipe (UFS). Membro do Instituto de Pesquisa em Educação e Educação Física (PROTEORIA). Sergipe, Brasil. E-mail: omarvix@gmail.com

** Doutor em Educação. Professor do Departamento de Desportos da Universidade Federal do Espírito Santo (CEFD-UFES). Coordenador do Instituto de Pesquisa em Educação e Educação Física (PROTEORIA). Vitória, Espírito Santo, Brasil. E-mail: amarilio@proteoria.org 1 Dissertação defendida no ano de 2003, no Programa de Estudos Pós-Graduados em Educação: História, Política, Sociedade da Pontifícia Universidade Católica de São Paulo, com o título A Revista Educação Physica (1932-1945): estratégias editoriais e prescrições educacionais.
} 


\section{Artigos Originais Omar Schneider e Amarílio Ferreira Neto}

circunscritos apenas ao Brasil, pois possuía correspondentes e representantes em vários países da América Latina, Europa e África Portuguesa. $^{2}$

Nas perspectivas iniciais dos editores da revista estava a intenção de reconhecimento como órgão orientador da Educação Física nacional, mas, no decorrer dos anos, esse propósito foi paulatinamente ampliado e, já no terceiro número, passam a almejar também que, ao circular em Portugal, servisse como elemento organizador da Educação Física naquele país. Desse modo, o impresso é apresentado como um instrumento que surgiu para apostolizar, no Brasil e em Portugal, a beleza e o ideal de uma raça mais completa e mais nobre, desenvolvida, ampla e simultaneamente, em todas as suas possibilidades (SCHNEIDER, 2003).

Para analisar os meios pelos quais os editores da revista $E d u$ cação Physica pretendiam implementar o projeto de fomentar no Brasil a produção de uma raça mais nobre e desenvolvida, mobilizamos a noção de Circularidade Cultural ${ }^{3}$ utilizada por Ginzburg (1987) que analisa as relações entre códigos culturais provenientes de grupos sociais distintos. Ao mesmo tempo, procura-se compreender como, no Brasil das décadas de 1930 e 1940, a partir das disputas entre diferentes padrões culturais que circulam na revista Educação Physica, se constrói a representação de "homem novo".

Para discutir o tema proposto utilizamos as reflexões produzidas no âmbito de um projeto de pesquisa desenvolvido na Pontifícia Universidade Católica de São Paulo no Programa de Pós-Graduação em Educação: História, Política, Sociedade, sob a coordenação da

\footnotetext{
2 A revista Educação Physica foi produzida por iniciativa de dois professores de Educação Física, Paulo Lotufo e Oswaldo Murgel Rezende, os quais foram seus dois primeiros diretores editores. Posteriormente a esses dois, somam-se outros, Roland de Souza e Hollanda Loyola.

3 Circularidade cultural é um conceito-chave para a Micro-História e faz parte das referências conceituais da História Cultural. Propõe-se, com base na circularidade cultural, que não se trabalhe com a relação cultura popular (entendida como subalterna) versus cultura erudita (entendida como dominante), como se houvesse uma barreira rígida que impedisse as relações de troca mútua. Desse modo, circularidade cultural é entendida como uma rede de relações materiais e simbólicas em que sempre há apropriações e transformações de materiais sociais pelos usos improvisados e inesperados, o que não permite que se pense em algo como cultura imposta (GINZBURG, 1987).
}

Movimento, Porto Alegre, v. 14, n. 01, p. 135-159, janeiro/abril de 2008. 
professora Mirian Jorge Warde. O projeto começou no ano 2001, mas possui suas proposituras já explicitadas em artigo veiculado em 2000 com o título Americanismo e educação: um ensaio no espelho. Já com o título Americanismo e educação: a fabricação do "homem novo", o projeto de 2001, segundo a autora, tinha como objetivo "[...] examinar o longo e tortuoso itinerário de produção da hegemonia norte-americana no Brasil" (WARDE, 2001a, p.7). Essa hegemonia, de acordo com a autora, não se construiu no sentido gramsciano, mas em um tipo específico que ocorre na disputa entre diferentes padrões culturais, de diferentes grupos. Nesse processo, são acionadas “[...] estratégias e táticas [...] [de] incorporação de elementos constitutivos de outros padrões culturais" (WARDE, 2001a, p. 5). Exatamente essa disputa entre padrões culturais, suas estratégias e táticas é que temos a intenção de compreender na constituição e configuração do campo pedagógico da Educação Física, deslocando o foco do sentido de influência para flagrar a produção do "homem novo" que se processa no embate entre diferentes modelos culturais.

Nosso estudo possui como foco o período anterior ao fim da Segunda Guerra Mundial, momento em que os Estados Unidos da América ainda estão produzindo sua hegemonia. Assim, em disputa com outros padrões culturais que buscam meios de afirmar seus valores, suas idéias e seus modelos se impõem como os melhores e mais modernos ou como aqueles que possuíam as melhores soluções para levar as outras culturas a entrarem na tão decantada modernidade.

Ao discutir como se constrói no Brasil o sentido de americanismo como resposta à busca de modernidade, entre meados do século XIX até as cinco primeiras décadas do século XX, Warde (2000, p. 37) comenta que há um deslocamento dos registros discursivos, os quais podem ser compreendidos "[...] mediante a passagem do foco do 'regime de governo' para o ‘sujeito' ou o 'homem novo' necessário à modernidade”. Para a autora, Gramsci via no americanismo uma:

[...] mudança radical de toda uma cultura cujo peso jamais poderia ser minimizado, posto que exercia a função de cimentar as reformas econômicas em curso

Movimento, Porto Alegre, v. 14, n. 01, p. 135-159, janeiro/abril de 2008. 


\section{Artigos Originais Omar Schneider e Amarílio Ferreira Neto}

(diria ele, o nome da reforma econômica é reforma intelectual e moral); de outro lado, Gramsci viu nessa cultura a operação de recriação do sujeito; ou seja, nos termos da época, o americanismo estava produzindo um 'homem novo' (WARDE, 2000, p 42).

Conforme Warde (2000, p. 43), o que estava se operando eram “[...] 'mudanças no modo de ser e viver' e como tal [...], [consistiase em um] processo de configuração subjetiva" que se podia compreender como a produção de uma nova conformação psicofísica, ou seja, estava se inventando um "homem novo". Assim, para a autora, ao se estudar o americanismo, o que se pretende verificar é:

[...] como, através de que mecanismos - discursivos e não-discursivos - o americanismo penetrou no Brasil e constituiu-se em cultura, moldou formas de pensar, sentir e viver; tornou-se parâmetro de progresso, felicidade, bem-estar, democracia, civilidade; de que modo o americanismo moldou as esperanças em torno da cidade e da indústria, projetou padrões de arquitetura; redimensionou espaços e acelerou os tempos; plantou nos corações e mentes a silhueta do 'homem novo' - racional, administrador e industrioso (WARDE, 2000, p. 43).

Utilizar como referência o sentido de americanismo sugerido por Warde (2001b), o qual, segundo a autora, pode ser projetado como uma rede de relações materiais e simbólicas, em que o ponto de inflexão é o campo da cultura, permite-nos o afastamento do sentido positivista de "influência". Assim, longe de projetar o estudo como meio de perceber as influências, como se existisse um local de emissão e outro de recepção das idéias ou representações pretendemos, ao ler os debates, perceber as representações compartilhadas ou em luta, a circulação das idéias e as trocas culturais no âmbito das práticas de apropriação (WARDE, 2001b). ${ }^{4}$

4 Ver também Bontempi Júnior (2005) no estudo Os intelectuais brasileiros e os significados educacionais da Guerra Franco-Prussiana e da Primeira Guerra Mundial. Para o autor esses dois acontecimentos são fundamentais para que se possa compreender a forma como as idéias relacionadas ao americanismo circularam, foram apropriadas e se tornaram ponto de acaloradas discussões entre os intelectuais brasileiro.

Movimento, Porto Alegre, v. 14, n. 01, p. 135-159, janeiro/abril de 2008. 


\section{INTELECTUAIS, REPRESENTAÇÕES, REGENERAÇÃO DA RAÇA E A CONSTRUÇÃO DO "HOMEM NOVO".}

A passagem do século XIX para o século XX é marcada por um intenso movimento de busca de modernização. A busca pelo moderno, pelo novo, pelo que deu certo em outros países aparece com grande força nas discussões relativas ao futuro do Brasil. A modernização do campo educacional é percebida como primordial para o desenvolvimento nacional, para a criação de novas mentalidades, já não arraigadas ao tradicionalismo imposto pela pedagogia de orientação jesuítica, mas orientado para a construção de um novo homem para uma nova sociedade que se anuncia. Os novos rumos visualizados necessitam de um homem que se adapte a um mundo em constante transformação. Desse modo, necessita-se de um homem educado, moral, física e socialmente. A educação passa a ser percebida como forma de produzir esse homem, ao mesmo tempo em que é elevada a ferramenta capaz de tirar o Brasil do atraso cultural em que permanecia, quando comparado com alguns países da Europa e da América do Norte (SCHNEIDER; FERREIRA NETO, 2006).

Nesse processo que deveria ser pedagógico, a educação do físico é compreendida como a possibilidade de atuar sobre o corpo, porém visando a educar não só o corpo, mas também a sensibilidade, a forma de perceber e agir sobre a realidade, criando nesse processo novas subjetividades. ${ }^{5}$ Não sem propósito, o ideário pedagógico que se elabora busca construir o discurso ${ }^{6}$ da educação integral em que, para se formar esse novo homem, dever-se-ia intervir tanto em seus aspectos intelectuais, quanto nos aspectos físicos e morais (SCHNEIDER; FERREIRA NETO, 2006).

\footnotetext{
5 Rui Barbosa (1946) nos seus pareceres sobre a instrução primária, divulgados no ano de 1883 , defendia que a intervenção na modificação dos costumes deveria ser realizada com base em uma intervenção sobre o corpo. Para o autor, com a intervenção feita por meio da educação do físico, os hábitos seriam mais bem assimilados. Conforme Rui Barbosa, intervindo sobre o corpo, as lições de moral poderiam ser "[...] talvez mais poderosas do que os preceitos inculcados verbalmente" (t. II, 1946, p. 99). Desse modo, Rui Barbosa, citado por Lourenço Filho (1966, 88, p. 22) compreendia que "[...] a reforma do método, não deveria ser [...] a simples alteração da mecânica escolar. Deveria ser a reforma dos costumes e da mentalidade de nossa gente". 6 A investigação aqui desenvolvida, de acordo com a metodologia adotada, trabalha contra uma perspectiva de análise dos discursos e das práticas como algo desvinculado de suas condições de produção e de circulação. Assim, discursos, aqui compreendidos, são "[...] matrizes de práticas construtoras do próprio mundo social” (CHARTIER, 1991, p. 183).
}

Movimento, Porto Alegre, v. 14, n. 01, p. 135-159, janeiro/abril de 2008. 


\section{Artigos Originais Omar Schneider e Amarílio Ferreira Neto}

Em momento não muito distante, o problema era encarado de outra forma. Não fazia sentido investir em políticas públicas orientadas para a educação, a saúde e o saneamento de um meio urbano e rural habitado por uma gente que se considerava triste e degenerada, ${ }^{7}$ pois esta já estava condenada pela raça e pelas leis da hereditariedade. Desse modo, pouco se poderia fazer. O melhor caminho seria a imigração, modo mais simples de melhorar as características raciais do brasileiro (SCHNEIDER; FERREIRA NETO, 2006).

Inspirados nos trabalhos de Cesare Lombroso (1983), ${ }^{8}$ médico legista muito festejado no final do século XIX, ${ }^{9}$ que propunha diagnosticar a possível tendência ao crime por meio da análise das características "somatotípicas" ${ }^{10}$ dos indivíduos, alguns intelectuais brasileiros ${ }^{11}$ não viam muitos caminhos para o Brasil tornar-se um País moderno, a não ser pelo branqueamento de sua população, o que somente seria possível, na opinião desses explicadores do Brasil, ${ }^{12}$ ser realizado por meio da imigração. ${ }^{13}$

7 "Numa terra radiosa vive um povo triste". Assim começa Paulo Prado (1997, p. 53) ensaio em que buscava, em fins da década de 1920, delinear a identidade e o caráter que o brasileiro teria herdado da experiência colonial. Fruto das teses que procuravam apontar os males de origem do brasileiro, o ensaio de Paulo Prado é uma síntese das representações sobre as diferenças das raças, que vinham animando os debates de boa parte da intelectualidade brasileira das décadas finais do século XIX e início do século XX.

8 Uma leitura necessária para se compreender as teorias que buscaram, em fins do século XIX e início do século XX, hierarquizar as raças humanas a partir do cálculo das características físicas é o estudo de Gould (1999), intitulado $A$ falsa medida do homem. Nesse livro, o autor aborda os testes que foram desenvolvidos por médicos com base no estudo da Anatomia e Antropometria para construir boa parte das teorias racistas que serviram de justificativas para se afirmar o que era normal e o que era patológico na conduta humana.

9 Conforme Cavalcanti Netto (1983, p. VI), "A certa altura, nenhuma pessoa de alguma cultura poderia ignorar Lombroso. Sua teoria revolucionaria todo o pensamento médico e jurídico de uma época. E o mundo, extasiado, perplexo, se prostrou aos pés do iluminado". 10 Para Lombroso, ao analisar as características físicas de um indivíduo, poder-se-ia perceber que "[...] em geral, o delinqüente nato tem orelhas de abano, cabelos abundantes, barba escassa, os senos frontais e as mandíbulas enormes, queixo quadrado e proeminente, zigomas aumentados, a gesticulação freqüente, em suma um tipo parecido com o mongol, às vezes com o negro" (LOMBROSO, 1983, p. 168).

11 De acordo com Schwarcz (1995), foi grande a utilização das proposições de Lombroso no meio acadêmico, principalmente do Direito, em áreas dedicadas ao estudo da Criminologia. 12 Conforme Leite (1992), vários ensaístas, como Silvio Romero e Euclides da Cunha, acreditavam que somente o branqueamento da população poderia salvar o Brasil da degenerescência. Citando Sílvio Romero, Leite (1992, p. 190) considera que este, ao apontar as características psicológicas do povo brasileiro, concluía pelo seu estado " [...] apático, sem iniciativa, desanimando'; na vida intelectual, imitação do estrangeiro".

13 Para Marques (1994, p, 88), "[...] a tarefa de 'aryanização' da raça ficava facilitada com a vinda de estrangeiros já que a população tornar-se-ia branca, sem que, para isso, as elites corressem o risco de perder seus pedigree. Mesmo sendo considerados socialmente inferiores, os imigrantes contribuíram para o "clareamento dos brasileiros" (grifo da autora).

Movimento, Porto Alegre, v. 14, n. 01, p. 135-159, janeiro/abril de 2008. 
As idéias de tornar o Brasil um País livre dos seus "males de origem", utilizando o expediente da imigração, são bem localizadas na historiografia, pois, por ocasião da Primeira Guerra Mundial, o cenário internacional e brasileiro, em relação aos emigrantes, se modifica.

Após a Primeira Grande Guerra, a posição dos intelectuais, quanto ao modo a ser empregado para se sanear e eugenizar o Brasil, também sofreu profundas modificações. Já não era possível contar com as levas de imigrantes europeus, modo mais fácil de mudar as características raciais dos brasileiros, transmutando de uma gente amorfa para uma sociedade com identidade racial definida pela brancura da pele, sinônimo de civilização e modernidade. Agora a fórmula ou tendência era apresentar o brasileiro como essencialmente bom, vítima, porém, da falta de educação (COUTO, 1994).

Com o refluxo das correntes imigratórias determinadas pela Primeira Grande Guerra e sob o impacto das greves operárias do final da década de 1910, as teorias racistas que, na economia das providências republicanas, haviam constituído a opção imigrantista como recurso civilizatório perdem um de seus pilares de sustentação. As teses racistas, que haviam sido articuladas em defesa da imigração, fundamentando práticas excludentes da participação do liberto no mercado de trabalho dos setores mais dinâmicos da economia nacional, são agora reformuladas (CARVALHO, 2003). Essa política de exclusão do liberto fundada na aposta racista de que a tão decantada operosidade do imigrante acabasse por erradicar a vadiagem nacional ruía, fazendo com que a incorporação das populações excluídas por sua lógica perversa se configurasse como problema posto para a escola (CARVALHO, 2003). "Vitalizar pela educação e pela higiene toda essa gente reduzida pela vermina a meio-homem, a um terço de homem, a um quarto de homem [...]" passa a se constituir como solução (COUTO, 1927, p. 14). ${ }^{14}$

Quando a aposta racista no branqueamento da população como efeito do processo imigratório se desmistifica, "organizar o trabalho

14 De acordo com Carvalho (2003, p. 14), “Regenerar as populações brasileiras, núcleo da nacionalidade, tornando-as saudáveis, disciplinadas e produtivas, eis o que se esperava da educação, erigida nesse imaginário em causa cívica de redenção nacional. Regenerar o brasileiro era dívida republicana a ser resgatada pelas novas gerações" (grifo da autora).

Movimento, Porto Alegre, v. 14, n. 01, p. 135-159, janeiro/abril de 2008. 


\section{Artigos Originais Omar Schneider e Amarílio Ferreira Neto}

nacional" com o concurso da escola passa a ser prioridade política. É, assim, que a escola começa a se impor no horizonte ideológico das elites políticas e intelectuais, como recurso consistente de incorporação generalizada das populações à ordem social e econômica (SCHNEIDER; FERREIRA NETO, 2006).

A figura que reinava no imaginário da intelectualidade brasileira e que tem sua síntese no Jeca-Tatu, personagem criado por Monteiro Lobato, em 1918, como meio de descrever o típico homem do interior, mobiliza imagens de um País assolado pela doença, decorrente da falta de saneamento, de nutrição e de instrução, mas também fruto do descaso dos governantes. Para os explicadores do Brasil das décadas de 1910 e 1920, o problema estava em como sanear as imensas populações de jecas-tatus espalhadas pelo território nacional, moralizar seus corpos e desmistificar "[...] o mobiliário cerebral do Jeca [...] [e] o suculento recheio de superstições [...]" (LOBATO, 1918, p. 286) que povoavam a sua mente.

O homem brasileiro passa a ser identificado como o Jeca-Tatu, representante de um país doente, assim com graves problemas para entrar na tão sonhada modernidade. Desse modo, o investimento sobre o corpo, também é um investimento que visa apresentar novos modelos de comportamento e organizar novas formas de lidar com a indigência do povo (SCHNEIDER; FERREIRA NETO, 2006).

\section{HOMEM NOVO: ESTRATÉGIAS DISCURSIVAS E REPRESENTAÇÕES COMPARTILHADAS}

A revista Educação Physica nasce, conforme seus editores, pela necessidade que percebiam de os professores de Educação Física ter acesso a um impresso que servisse como meio de fazer circular os ideais da verdadeira educação, o que para eles consistia em levar em consideração as três dimensões do processo educativo: a intelectual, a moral e a física. Segundo os editores, "[...] os grandes educadores têm proclamado com eloqüência, com profunda verdade, a complexidade e o alcance da verdadeira e moderna educação" (EDITORIAL, 1934, p. 11).

Movimento, Porto Alegre, v. 14, n. 01, p. 135-159, janeiro/abril de 2008. 
Ao trabalhar com essas três dimensões, para os editores, a educação moderna alcançaria o seu objetivo, que seria "[...] crear o homem integral, o homem forte physica, moral e intellectualmente" (EDITORIAL, 1934, p. 11). Compreendendo que essa necessidade se configurava em "[...] uma força de grande possibilidade creadora [...] [apontam os objetivos de fundo da publicação. Para eles, com a implementação da revista, surgia uma] compreensão mais lata e mais nobre da educação physica, ou melhor, da educação" (EDITORIAL, 1934, p. 11).

Segundo os editores pela veiculação do periódico, pelo incentivo e pela prescrição de novas práticas na sociedade, "[...] homens novos, homens mais fortes, homens melhores [...] [poderiam] surgir" (EDITORIAL, 1934, p. 11). Para os editores, a hora que estavam vivendo era incerta. Percebem que o País estava passando por um momento de tormentória transição, mas que, ao mesmo tempo, era um período que possuía grande possibilidade criadora. Nesse sentido, percebiam que aquele era um momento de investimentos, não só para se educar os leitores do impresso, mas também o Estado para que fosse possível produzir homens novos, mais fortes e melhores. Para os editores, a "'Educação Physica' não visava apenas suggerir, propagar, fazer compreender. 'Educação Physica' desejava persuadir, estimular, levar a realizar" (EDITORIAL, 1934, p. 11).

$\mathrm{Na}$ empreitada de definir um novo modelo para a Educação Física, os editores do impresso traduzem para a revista uma matéria publicada originalmente em uma revista norte-americana dedicada aos esportes, assinada pelo Dr. Irving Fisher. ${ }^{15}$ A matéria apresentava-se com o seguinte título: A nova Educação Physica.${ }^{16} \mathrm{De}$ acordo com o autor,

\footnotetext{
15 Irving Fisher (1867 - 1947), professor de Política, Economia e Matemática da Universidade de Yale nos Estados Unidos.

16 Durante o período em que a revista circula, essa mesma matéria é veiculada seis vezes. Ela é a única que por tantas vezes é reeditada, demonstrando que os editores, de certa forma, concordavam com as idéias que por ela eram explicitadas. A matéria que conclama os professores para assumirem uma nova Educação Física foi veiculada nos seguintes números: 4 (1934); 9 (1937); 13 (1937); 25 (1938); 32 (1939) e 73 (1943). Junto à matéria, como dispositivo de convencimento, vinha uma nota explicativa sobre a autoridade do $\mathrm{Dr}$. Fisher no assunto que se tratava e uma sugestão feita pelos editores do impresso sobre a necessidade de o conteúdo da matéria ser veiculada em outros suportes. Diziam eles: "Suggerimos a transcripção deste artigo nas secções de esporte dos jornaes e revistas" (FISHER, 1934, p. 13).
}

Movimento, Porto Alegre, v. 14, n. 01, p. 135-159, janeiro/abril de 2008. 


\section{Artigos Originais Omar Schneider e Amarílio Ferreira Neto}

[...] a edade nova requer homens de iniciativa, vivos, criteriosos. Será necessario, portanto, empregar typos de actividade que desenvolvam essas qualidades. Estas caracteristicas desenvolvem-se geralmente nos jogos. O jogo é creador e poetico. Tem grande valor como estimulante da imaginação. [...] a nova educação physica deve ser antes objetiva que subjetiva. A gymmastica do passado era subjetiva. Os esportes actuaes são objetivos. Naquella, a grande preocupação estava na forma e na maneira de executar um determinado exercicio. Neste, o que importa são os resultados, como, por exemplo, fazer a bola passar uma determinada linha para marcar um goal. Antigamente, dava-se valor ao equipamento e aos materiaes a empregar. Agora, aos indivíduos que com elles serão beneficiados. A edade moderna precisa de homens efficintes e optmistas. A nova educação physica dará, por isso, grande importancia á hygiene. Ensinará o homem a viver da melhor maneira possível. Fará com que cada um dos seus habitos physicos contribua para o aumento da sua efficacia e não para a sua diminuição. [...] antes os jogos athleticos tinham valor como espetáculo. Agora a participação nelles é que vale (FISHER, 1934, p. 13).

O que propõe o Dr. Fisher é uma redefinição dos objetivos da Educação Física. Se antes a preocupação era com a forma e a maneira de executar os movimentos, na idade nova, como sugere o doutor, o que mais importa são os resultados. Para isso, nada melhor que a objetividade dos esportes.

Fruto direto da modernidade, o fenômeno esportivo, pela sua peculiaridade de atividade física, regrado por regulamentos, assume características que o distingue das outras formas de exercitação corporal, como: especialização dos papéis, competição, cientifização, rendimento, quantificação, recorde e racionalização do treinamento. São essas condições objetivas que podem ser medidas, quantificadas e comparadas que, na visão do Dr. Fisher, faziam com que o esporte fosse o melhor meio de preparar o novo homem. Nota-se que a nova Educação Física toma como referência o modelo da fábrica e o que passa a importar são os resultados. Para o Dr. Fisher, a nova Educação

Movimento, Porto Alegre, v. 14, n. 01, p. 135-159, janeiro/abril de 2008. 
Física, entenda-se esporte, deveria contribuir para que os hábitos físicos desenvolvidos durante as aulas fossem mais eficientes/ especializados, o que significa maior rendimento, com o mínimo de tempo e de esforço.

Na mesma matéria em que o Dr. Fisher apresenta as características essenciais para preparar o "homem novo" a enfrentar o novo tempo, também revela quais representações do povo brasileiro, os editores pretendiam compartilhar com os leitores do impresso. Compreende-se assim, a finalidade pela qual a Educação Física deveria ser implementada nas escolas e clubes e a qual tipo de homem tinhase por objetivo produzir no Brasil. Assim o autor escreve:

\section{[...] a nova educação physica deverá formar um homem typico que tenha as seguintes caracteristi- cas: detalhe mais delgado que cheio, gracioso de musculatura, flexivel, de olhos claros, pelle sã, ágil, desperto, erecto, dócil, enthusiasta, alegre, viril, imaginoso, senhor de si mesmo, sinsero, honesto, puro de actos e de pensamentos, dotado com o senso de honra e da justiça, compartilhando no companheirismo dos seus semelhantes (FISHER, 1934, p. 13-14).}

Na produção de uma discursividade que exorcizasse os males de origem, tema que se tornou pauta obrigatória dos explicadores do Brasil das primeiras décadas do século XX, os editores do impresso são bem-sucedidos, pois as representações que são veiculadas são apropriadas por outros atores do mesmo período. ${ }^{17}$

Para que a representação fabricada de "homem novo", seguindo os conselhos do Dr. Fisher, fosse a "vencedora", ampla discussão pode-se captar em relação ao sentido do esporte em contraposição à ginástica, principalmente a que se configura como Método Alemão e Método Sueco.

Em 1938, Américo R. Netto ${ }^{18}$ publica uma matéria com o seguinte título: Gymnastica ou esporte: alguns critérios para

17 O referencial para se projetar o homem do amanhã aparece citado por Guiomar Meirelles Becker, na introdução de um livro de sua autoria, publicado em 1942, na cidade de Belo Horizonte, com o título Educação física infantil.

18 Professor da Escola Superior de Educação Physica do Estado de São Paulo.

Movimento, Porto Alegre, v. 14, n. 01, p. 135-159, janeiro/abril de 2008. 


\section{Artigos Originais Omar Schneider e Amarílio Ferreira Neto}

differencial-os. Para o autor, um dos diferenciadores que poderiam ser destacados e que com certeza colocava as duas atividades em pólos diferentes era o espírito de competição, que assim poderia ser descrito:

[...] este espírito [de competição], que é o propósito de fazer mais ou melhor, em confronto com outro não existe - ou pelo menos, 'não deve' existir - na gymnastica, cujos effeitos educativos seria por ela perturbados, possivelmente anulados. No esporte, entretanto, a luta contra qualquer antagonista, seja pessôa, seja coisa, constitúe innegavelmente sua propria razão de ser, dando exemplo e estimulo tanto a quem o assiste. [...] a gymnastica [...] busca o homem normal, médio [...] o esporte, entretanto, procura sempre as excepções, quer de pessôas, quer de resultados, levando a criatura humana a forçosamente se destacar do seu grupo, pelas affirmações isoladas da sua efficiencia individual. Para elle a generalidade praticamente não tem valor. [...] elle sempre está differenciando e especialisando, num propósito de accentuada seleção, que leva o homem a competir não só com outros homens vivos, mas também com outros que já morreram, quando não com elle próprio. [...] Lutar, competir, exceder-se taes são as palavras de ordem da vida esportiva, quando a da gymnastica é o nivelamento do grupo, no qual o homem desdenha o esforço de fazer mais e melhor, apenas para fazer igual (NETTO, 1938, p. 15.).

Américo R. Netto ainda destaca outra particularidade em que se poderiam fundamentar os leitores/professores para diferenciar a ginástica e o esporte. Essa distinção se caracterizava pelo modo de avaliar os resultados oferecidos por uma e outra forma de exercitação. Assim descreve,

[...] no esporte a possibilidade [...] de medir numericamente o resultado do exercicio está sempre presente, seja feita de modo directo e absoluto, seja indirecta e relativamente, em comparação com outro resultado. Taes medidas são apreciadas em tempo, espaço e peso e por outros critérios menos

Movimento, Porto Alegre, v. 14, n. 01, p. 135-159, janeiro/abril de 2008. 


\begin{abstract}
freqüentes, mas sempre apreciados. $\mathrm{O}$ feito de um corredor de 200 metros pode ser definido comprehendido - em segundos e frações de segundo, como o lanço de um arremessador pode ser fixado em metros e centímetros. [...] Como porém, avaliar o resultado obtido por um gymnasta, ao fim de certo tempo de determinado exercícios? [...] não se pode pensar em oppôr o resultado em questão ao de outro gymnasta e com elle comparal-o, tirando deste confronto qualquer conclusão interessante ou util [...] só com elle proprio pode ser comparado, para se poder affirmar si progrediu, estacionou ou regrediu. [...] somente confrontado suas medidas anthropo-biologicas e contrastando suas capacidades funcionais é que se pode chegar a uma conclusão de real significação pratica (NETTO, 1938, p. 15).
\end{abstract}

A racionalidade e os "novos códigos" que o esporte desperta para a "Educação Física", os saberes que apresenta como científicos, a nova capacidade disciplinadora que oferece em que a eficiência pode ser medida em décimos de segundo, comparada e generalizada, trazem para o âmbito da Educação Física formas inéditas de intervenção disciplinar. O professor, de posse desses saberes, poderia ter um ferramental que possibilitaria descobrir e conduzir as potencialidades do educando de maneira a alcançar o máximo de produção, em termos de velocidade, força e resistência nos esportes, com o mínimo de tempo e de energias gastas.

Para Carvalho (1997), em estudo designado Quando a história da educação é a história da disciplina e da higienização das pessoas, os discursos educacionais das quatro primeiras décadas do século XX sofrem uma sutil mutação. O discurso pedagógico, que vinha se auto-afirmando desde o final do século XIX como moderno, experimental e científico, que voltava suas preocupações para a ortopedia como arte da correção da deformação, toma um novo caminho e as figuras:

[...] da deformação, que assombravam a produção discursiva anterior e que traziam a detecção e o controle da anormalidade para o âmago da

Movimento, Porto Alegre, v. 14, n. 01, p. 135-159, janeiro/abril de 2008. 


\section{Artigos Originais Omar Schneider e Amarílio Ferreira Neto}

pedagogia, são como que gradativamente expelidas do campo pedagógico e produzidas como tema e objeto da intervenção de outros saberes e poderes (CARVALHO, 1997, p. 280).

Conforme Carvalho (1997), o processo de corrosão gradativa que se abateu sobre o modelo educacional em que disciplinar se configurava como práticas de prevenção e correção:

[...] não derivou apenas $[\ldots]$ de mutações nos paradigmas científicos. No Brasil, ele foi decisivamente marcado pelas motivações políticas, sociais e econômicas que confluíram no chamado 'entusiasmo pela educação', movimento que reuniu intelectuais de diferentes categorias profissionais - principalmente professores, médicos e engenheiros - na propaganda da 'causa educacional' (CARVALHO, 1997, p. 280).

A intensificação do capitalismo industrial no Brasil, que a "Revolução de 1930" proporcionou, determinou na mesma ordem o desaparecimento e o aparecimento de novas exigências educacionais. As exigências da sociedade industrial impunham modificações profundas na forma e no modo de se encarar a educação, pois novas relações de produção colocavam-se na ordem do dia (SCHNEIDER, 2003).

As novas práticas visualizadas pela Pedagogia da Escola Nova, para Carvalho (1997), entram em cena redefinindo princípios e objetivos, livrando-se dos limites postos pelo cientificismo e apresentando-se otimistas em relação ao poder da educação. De acordo com a autora, tratava-se:

[de] apostar no poder disciplinador do processo que essa 'nova compreensão' entrevia embutido no processo de racionalização das relações sociais sob o modelo da fábrica. A regra que organizava as novas práticas pedagógicas não deriva mais, senão mediatizadamente, da ciência. Ele é metáfora dos ritmos impostos aos corpos e às mentes pela Vida moderna, império da indústria e da técnica (CARVALHO, 1997, p. 280).

Movimento, Porto Alegre, v. 14, n. 01, p. 135-159, janeiro/abril de 2008. 
Desse modo, as inovações que a nova Pedagogia coloca em cena, conforme Carvalho (1997, p. 285) passam a produzir novas sensibilidades e novos ritmos na sociedade, os quais "[...] faziam entrever modalidades inéditas de intervenção disciplinar. Assim, por exemplo, caberia ao professor 'guiar' a 'liberdade' do aluno de modo a garantir que o 'máximo de frutos' fosse 'obtido com um mínimo de tempo e esforço perdido", o que resulta que eficiência passa a ser o objetivo da disciplina, desse modo, "[...] disciplinar não é mais prevenir ou corrigir. É moldar" (CARVALHO, 1997, p. 286).

Interessante notar que o deslocamento que redefine o que deveria ser entendido por Educação Física não ocorre sem tensões e resistências.

Fernando de Azevedo, em matéria escrita em 1938 para a revista Educação Physica, tratando sobre as tendências da Educação Física na Escola Anglo-Americana, tece severas críticas à predominância que o esporte havia obtido na Inglaterra e nos Estados Unidos e à propensão que estava observando nas escolas brasileiras em copiar o exemplo desses países. Para Fernando de Azevedo, isso ocorria por haver uma "[...] má comprehensão do papel que cabe aos esportes aos quais se pretende erroneamente reduzir toda a educação physica" (AZEVEDO, 1938, p. 9), e também pelo fato de as instituições/professores não perceberem que "[...] os esportes são, apenas um meio e não um fim [grifos do autor]" (AZEVEDO, 1938, p. 9).

Para Fernando de Azevedo (1938), o esporte deveria ser preferencialmente recreativo e deveria ser realizado somente depois da seção de ginástica, a qual prepararia o organismo para o esforço que os esportes exigiriam dos alunos. Assim conclui o autor: "[ [... se condemnamos, em summa, os esportes como methodo exclusivo de educação physica escolar, não lhes podemos negar sua grande utilidade" (AZEVEDO, 1938, p. 11), na distração necessária entre as horas de aula, respondendo, desse modo, às inquietudes físicas dos alunos.

Como se pode perceber, mesmo que houvesse a negação do esporte como o conteúdo principal a ser ensinado pela Educação

Movimento, Porto Alegre, v. 14, n. 01, p. 135-159, janeiro/abril de 2008. 


\section{Artigos Originais Omar Schneider e Amarílio Ferreira Neto}

Física no ambiente escolar, ele já era uma realidade no âmbito educacional. Desse modo, não poderia ser negado como saber a ser utilizado na docência. Mas, para ser utilizado, era necessário que lhe diminuísse o caráter utilitário e subordiná-lo ao ritmo da ginástica, o que faria com que perdesse algumas de suas marcas de produção/origem, como: competição, especialização e quantificação dos resultados. Essa proposta é bem diferente da veiculada na matéria escrita pelo Dr. Fisher, para o qual o resultado era a medida da eficiência/especialização adquirida.

\section{Presença americana na ReVista Educação Physica}

Na revista Educação Physica, muitas são as referências que podem ser atribuídas à presença americana na constituição da discursividade que o impresso faz circular, mas essa não é a única forma de constatar a presença americana no impresso. Quando comparamos o número de autores, 804, que publicam ou são publicados no impresso, percebemos que, das 1.116 matérias, a que podem ser atribuídas autoria, 258 são provenientes dos Estados Unidos da América. Dos 399 autores que podem ser identificados, 155 são americanos, número bem próximo dos autores brasileiros, 172 , que publicam matérias originais e traduzidas de outros países. O Quadro 1, a seguir, mostra como se distribui a autoria/origem das matérias publicadas na revista Educação Physica.

\begin{tabular}{|l|c|c|}
\hline País & Número de autores & Número de matérias \\
\hline Brasil & 172 & 671 \\
\hline Estados Unidos & 155 & 258 \\
\hline França & 22 & 59 \\
\hline Argentina & 12 & 64 \\
\hline Itália & 6 & 9 \\
\hline Uruguai & 6 & 18 \\
\hline Alemanha & 5 & 7 \\
\hline
\end{tabular}

Movimento, Porto Alegre, v. 14, n. 01, p. 135-159, janeiro/abril de 2008. 


Continuação
\begin{tabular}{|l|c|c|}
\hline País & Número de autores & Número de matérias \\
\hline Chile & 5 & 5 \\
\hline Bélgica & 2 & 2 \\
\hline Japão & 2 & 2 \\
\hline Peru & 2 & 2 \\
\hline Suécia & 2 & 7 \\
\hline Áustria & 1 & 1 \\
\hline Canadá & 1 & 1 \\
\hline Espanha & 1 & 1 \\
\hline Hungria & 1 & 1 \\
\hline Inglaterra & 1 & 1 \\
\hline Portugal & 1 & 5 \\
\hline Suiça & 1 & 1 \\
\hline Venezuela & 1 & 1 \\
\hline Não Identificadas & 405 & 471 \\
\hline Total & $\mathbf{8 0 4}$ & $\mathbf{1 5 8 7}$ \\
\hline
\end{tabular}

Quadro 1 - Origem das matérias publicadas entre 1932 e 1945

Como se percebe, o número de autores e matérias provenientes de outros países é bem inferior ao número de autores e matérias provenientes dos Estados Unidos da América. Acreditamos que o superior número de matérias provenientes dos Estados Unidos da América deva-se ao número de colaboradores que auxiliavam os editores do impresso na captação e/ou tradução dos artigos publicados.

Quando observamos o número de colaboradores que são designados pelos editores como aqueles que dão suporte ao impresso, percebemos que, dos 33 que são apresentados aos leitores, 14 possuem algum tipo de ligação com a Associação Cristã de Moços (A. C. M.), instituição inglesa criada em 1844. A A.C. M. tinha, entre suas funções, divulgar os esportes e formar professores para atuar em clubes e escolas. Chegou aos Estados Unidos em 1851 e de lá foi trazida ao Brasil pelo missionário americano Myron Clark, o qual fundou, em 1893, no Rio de Janeiro, a primeira sede na América

Movimento, Porto Alegre, v. 14, n. 01, p. 135-159, janeiro/abril de 2008. 


\section{Artigos Originais Omar Schneider e Amarílio Ferreira Neto}

Latina. ${ }^{19} \mathrm{O}$ Quadro 2, a seguir, indica apenas os quatorze colaboradores apresentados pelos editores da revista Educação Physica que mantinham relações diretas com a A. C. M:

\begin{tabular}{|c|c|}
\hline Cola & Formação e atividade profissional ${ }^{20}$ \\
\hline Dr. Arthur Brasil & $\begin{array}{l}\text { Líder da Educação Física na A. C. M. do Rio de Janeiro. Um } \\
\text { dos fundadores de "Educação Physica" }\end{array}$ \\
\hline $\begin{array}{l}\text { Dr. Howard Webster } \\
\text { Adams }\end{array}$ & $\begin{array}{l}\text { Advogado norte-americano das Empresas Elétricas do Brasil, } \\
\text { técnico formado pela A. C. M. Americana, líder do voleibol } \\
\text { nos Estados Unidos, na Europa e atualmente no Brasil }\end{array}$ \\
\hline Fred Brown & $\begin{array}{l}\text { Norte-americano formado pela Escola Superior de Educação } \\
\text { Física de Chicago. Técnico da Federação Brasileira de } \\
\text { Futebol e da Federação Brasileira de Basquetebol - Líder da } \\
\text { Educação Física no Brasil. Treinador do Fluminense Futebol } \\
\text { Clube e membro da Associação Brasileira de Educação } \\
(\text { ABE) }\end{array}$ \\
\hline $\begin{array}{l}\text { Prof. Asdrubal } \\
\text { Monteiro }\end{array}$ & $\begin{array}{l}\text { Diplomado pelo Instituto Técnico de educação Física das A. } \\
\text { C. M. (Montevidéu) - Prof. da A.C.M. do Rio de Janeiro }\end{array}$ \\
\hline Prof. Cyro & $\begin{array}{l}\text { Diplomado pelo Instituto Técnico das A. C. M. (Montevidéu) } \\
\text { Diretor do Departamento de educação Física da A. C. M. do } \\
\text { Rio de Janeiro }\end{array}$ \\
\hline $\begin{array}{l}\text { Prof. Dr. James S. } \\
\text { Summers }\end{array}$ & $\begin{array}{l}\text { Professor de Educação Física norte-americano, diretor do } \\
\text { Instituto Técnico de Educação Física das A. C. M. Sul } \\
\text { Americanas (Montevidéu) }\end{array}$ \\
\hline Prof. Ernesto Opplinger & $\begin{array}{l}\text { Diplomado pelo Instituto Técnico de Educação Física das A. } \\
\text { C. M. (Montevidéu) - Prof. Da A.C.M. de São Paulo }\end{array}$ \\
\hline Prof. Henry J. Sims & $\begin{array}{l}\text { Ex-Diretor do Departamento de Educação Física da A. C. M. } \\
\text { do Rio de Janeiro - Instrutor e introdutor do basquetebol e } \\
\text { voleibol no Brasil }\end{array}$ \\
\hline Prof. João Lotufo & $\begin{array}{l}\text { Diplomado pelo Instituto Técnico de Educação Física das A. } \\
\text { C. M. (Montevidéu) - Diretor do Departamento de Educação } \\
\text { Física de São Paulo }\end{array}$ \\
\hline $\begin{array}{l}\text { Prof. José Rothier } \\
\text { Duarte }\end{array}$ & $\begin{array}{l}\text { Diplomado pelo Instituto Técnico de Educação Física das A. } \\
\text { C. M. - (Montevidéu) - Prof. de Educação Física da A. C. M. } \\
\text { do Rio de Janeiro }\end{array}$ \\
\hline
\end{tabular}

continua..

19 Apesar de a A. C. M. ter sido criada na Inglaterra, nos Estados Unidos teve grande desenvolvimento. Os principais esportes coletivos (basquetebol e voleibol) que passaram ser veiculados na revista Educação Physica foram criados por instrutores/professores de Educação Física que atuavam em A. C. M. americanas. A própria revista Educação Physica divulga em seu primeiro número, lançado em 1932, somente matérias relacionadas ao basquetebol, tanto tratando das regras do jogo como de seus aspectos técnicos.

Movimento, Porto Alegre, v. 14, n. 01, p. 135-159, janeiro/abril de 2008. 
continuação

\begin{tabular}{|l|l|}
\hline Colaboradores & Formação e atividade profissional $\mathbf{2 0}^{\mathbf{0}}$ \\
\hline $\begin{array}{l}\text { Prof. Oswaldo } \\
\text { Magalhães }\end{array}$ & $\begin{array}{l}\text { Diplomado pelo Instituto Técnico de Educação Física das A. } \\
\text { C. M. - (Montevidéu) - Prof. de ginástica da Rádio Nacional }\end{array}$ \\
\hline $\begin{array}{l}\text { Prof. Renato Eloy de } \\
\text { Andrade }\end{array}$ & $\begin{array}{l}\text { Diplomado pelo Instituto Técnico de Educação Física das A. } \\
\text { C. M. - (Montevidéu) - Diretor de Educação Física no Estado } \\
\text { de Minas Gerais }\end{array}$ \\
\hline Prof. Sylas Raeder & $\begin{array}{l}\text { Diplomado pelo Instituto Técnico de Educação Física das A. } \\
\text { C. M. - (Montevidéu) - Prof. da A. C. M. no Rio de Janeiro }\end{array}$ \\
\hline
\end{tabular}

Quadro 2 - Colaboradores na revista Educação Physica entre 1932-1945

Muitos dos professores envolvidos com a revista Educação Physica no Brasil não tinham o curso superior ou o secundário de Educação Física, mas apenas diploma de técnicos em esportes pela A. C. M. Mesmo um dos diretores do impresso, Paulo Lotufo, tinha realizado sua formação no Instituto Técnico de Educação Física da Associação Cristã de Moços da América do Sul, em Montevidéu.

A simples presença de americanos ajudando a compor o grupo de colaboradores que dava suporte ao impresso, ou professores formados em uma instituição com forte presença norte-americana não caracteriza a revista como um veículo de divulgação dos ideários ou representações norte-americanas a respeito da produção do "homem novo". Ocorre que muitas das imagens, tanto iconográficas como discursivas, remetem para a Alemanha, e mesmo a representação que esteticamente representava o "homem novo" fazia parte do ideário nazista em que o biótipo era o do homem europeu caucasiano. Mas como foi discutida a construção da hegemonia americana no plano cultural é produzida pela incorporação de elementos constitutivos de outros padrões culturais, ou seja:

[...] o americanismo foi se constituindo no interior mesmo dos Estados Unidos na luta entre diferentes/opostos projetos societários; o americanismo

20 A formação e atividade profissional dos colaboradores e autores que publicaram na revista Educação Physica era divulgada no impresso como meio de dar a ver, aos leitores, a autoridade de quem participava do periódico, escrevendo, coletando ou traduzindo artigos. Uma relação de todos os autores e colaboradores que publicaram ou participaram da confecção da revista pode ser acessada na dissertação de Schneider (2003).

Movimento, Porto Alegre, v. 14, n. 01, p. 135-159, janeiro/abril de 2008. 


\title{
154 Artigos Originais Omar Schneider e Amarílio Ferreira Neto
}

não é a hegemonia para o mundo extra-americano de um padrão que nasceu hegemônico no interior dos Estados Unidos; a hegemonia do americanismo no mundo extra-norteamericano é a própria contra-face do processo de hegemonização de algumas formas e padrões culturais e a subordinação de outros. Dito de outro modo, o americanismo é também a expressão histórica de um padrão cultural que se fez vitorioso no interior do próprio Estados Unidos, em meio a lutas intestinas, nada idílicas (WARDE, 2001b, p. 4).

Desse modo, é possível perceber algumas matérias escritas por norte-americanos exaltando a condição da Educação Física e dos esportes na Alemanha. Entre elas, uma escrita pelo professor norte-americano, Jackson R. Sharman (Diretor de Saúde e Educação Física da Universidade do Alabama), que discorre sobre $A$ educação profissional dos professores de Educação Physica na Allemanha. De acordo com o professor, “[...] os ideaes educativos que ora se acham em grande voga na Allemanha são aquelles expressados por Adolf Hitler e propagados pelo Nacional Socialismo" (SHARMAN, 1938, p. 11). Conforme o professor, os ideais veiculados por esse regime pretendiam o retorno de uma educação que preparasse para a vida, em que:

\begin{abstract}
As escolas de um Estado Nacional deverão dedicar mais horas para o desenvolvimento do corpo. Não deveria passar-se só dia em que o menino não dispusesse de uma hora inteira para o exercicio corporal, tanto de manhã como de tarde [...]. Nos membros mais novos da nação, a partir da infancia, toda a educação e treino deverão visar incutir em cada qual a convicção da sua superioridade sobre os demais (SHARMAN, 1938, p. 11).
\end{abstract}

Citando Hitler, o professor Sharman assim descreve as qualidades que a escola deveria desenvolver/cultivar por meio da Educação Física nos jovens:

[...] a obra educativa do Estado Nacional deverá collocar em grande proeminencia a formação do caracter passo a passo com a cultura do corpo... O

Movimento, Porto Alegre, v. 14, n. 01, p. 135-159, janeiro/abril de 2008. 
jovem allemão do futuro deverá ser a nossos olhos, esbelto e vigoroso, veloz como o lebreu, rigido como o couro, e duro como o aço Krupp (SHARMAN, 1938, p. 11).

Após analisar os modos pelos quais ocorre a presença americana na revista Educação Physica e as representações compartilhadas, vale lembrar, conforme Warde (2001a, p. 6), que:

\begin{abstract}
o [...] americanismo como hegemonia dos Estados Unidos sobre o mundo externo é resultado da hegemonia interna de alguns dos projetos em disputa, assim como é a incorporação de projetos e padrões culturais nascidos fora das fronteiras sociais dos Estados Unidos.
\end{abstract}

\title{
5 ConsideraçõEs FINAIS
}

Em uma sociedade que se projeta para ser competitiva, em que o paradigma educacional orienta-se segundo o molde da fábrica, em que o ritmo da cidade insiste que o homem seja cada vez mais competitivo e especializado a fabricação do "homem novo", integrado biopsicossocialmente à modernidade, pelo que se pode apreender dos discursos veiculados, passa a ser um dos objetivos perseguidos pelos editores do impresso. Ao ler as matérias veiculadas, percebe-se que a modernidade pretendida pelos editores estava circunscrita a algumas regiões da Europa e América do Norte.

Pelas proposições veiculadas pelo Dr. Fisher, se percebe uma nova orientação para a formação do sujeito, uma reforma intelectual e moral que se configuraria em uma transformação dos hábitos, resultando em um aumento da eficácia perante as demandas da sociedade ou do trabalho. Disciplinamento em que a eficiência poderia ser medida em décimos de segundo, comparada e generalizada. As possibilidades que o procedimento oferece possuía como objetivo a produção do que poderíamos denominar como novas representações sobre o valor do trabalho, que mesmo que não fossem materializadas corporalmente, por meio de um significativo aumento da eficiência, pelo menos seriam projetadas para serem gravadas

Movimento, Porto Alegre, v. 14, n. 01, p. 135-159, janeiro/abril de 2008. 


\section{Artigos Originais Omar Schneider e Amarílio Ferreira Neto}

nas consciências de quem passasse pelo processo educativo e se convertessem em um parâmetro da nova racionalidade sobre os usos do corpo em uma sociedade industrializada.

É possível perceber as representações sobre o que seria o "homem novo": são construídas por meio de apropriações em que diferentes padrões culturais são mesclados, revelando a tentativa de, por meio do discurso, produzir a imagem de um homem industrioso, eficiente e que revelariam no corpo as marcas da modernidade.

A cultura esportiva veiculada por meio da revista Educação Physica fazia parte de um movimento mais geral de difusão da cultura Norte-Americana sobre a América Latina, os editores representantes da Associação Cristã de Moços acreditavam serem os apóstolos da Educação Física que possuíam um evangelho a ser compartilhado com a sociedade. $\mathrm{O}$ discurso de boas novas afirmava a possibilidade de transformar um país recentemente saído de uma realidade escravocrata em uma nação com possibilidades de se integrar no concerto da modernidade, plasmando todas as raças em um tipo novo pronto para enfrentar um futuro glorioso (SCHNEIDER, 2003).

Longe do sentido de influência percebemos ao examinar a revista Educação Physica, a circulação da cultura, processos de apropriação, usos e transformações de discursos e representações que, no período em que o impresso é editado, estão à disposição dos intelectuais, tanto da Educação como da Educação Física.

Movimento, Porto Alegre, v. 14, n. 01, p. 135-159, janeiro/abril de 2008. 
Americanization and the "new man" invention: circulation and cultural model of appropriation in the magazine educação physica $(1932-1945)$ Abstract: It aims at exploring the hypothesis that sports culture propagated through the magazine Educação Physica was part of a more general movement of the North American culture diffusion in Latin America. To work on that hypothesis it is necessary to examine, very detailed, the cultural pattern vulgarized by the magazine, as result of appropriations and assimilations of other cultural patterns in dispute by the construction of a modernist model able to promote the production of a "new man" ready to face the contingences of social, political and economical changes concretized by the 30 s and 40 s.

Keywords: Educação Physica Magazine. Anthropology, cultural. Cultural characteristics. United States.

Americanismo y la fabricación del "hombre nuevo": circulación y apropiación de modelos culturales en la revista educação physica (1932-1945)

Resumen: Intenta explorar la hipótesis de que la cultura deportiva transmitida por medio de la revista Educação Physica era parte de un movimiento más general de difusión de la cultura norteamericana sobre América Latina. Trabajar con esa hipótesis significa examinar, muy detenidamente, el patrón cultural vulgarizado por la revista Educação Physica, como resultado de apropiaciones y asimilaciones de otros patrones culturales en disputa por la construcción de un modelo modernizador capaz de fomentar la producción de un "hombre nuevo" preparado para enfrentar las contingencias de las transformaciones sociales, políticas y económicas que las décadas de 1930 y 1940 concretizaron.

Palabras-clave: Revista Educação Physica. Antropología cultural. Características culturales. Estados Unidos.

\section{REFERÊNCIAS}

AZEVEDO, Fernando. Escola anglo-americana: predominância esportiva. Educação Physica, Rio de Janeiro, n. 14, p. 9-12, jan. 1938.

Movimento, Porto Alegre, v. 14, n. 01, p. 135-159, janeiro/abril de 2008. 


\section{Artigos Originais Omar Schneider e Amarílio Ferreira Neto}

BARBOSA, Rui. Reforma do ensino primário e várias instituições complementares da instrução pública. Obras completas. Rio de Janeiro: Ministério da Educação e Saúde, 1946.

BECKER, Guiomar Meirelles. Educação física infantil. Belo Horizonte: Imprensa Oficial de Minas Gerais, 1942.

BONTEMPI JÚNIOR, Bruno. Os intelectuais brasileiros e os significados educacionais da guerra franco-prussiana e da Primeira Guerra Mundial. In: SIMPÓSIO NACIONAL DE HISTÓRIA - HISTÓRIA: GUERRA E PAZ, 22., 2005, Londrina. Anais... Londrina: Editorial Mídia, 2005. p. 143-150.

CARVALHO, Marta Maria Chagas de. A escola e a república e outros ensaios. Bragança Paulista: EDUSF, 2003.

Molde nacional e fôrma cívica: higiene moral e trabalho no projeto da Associação Brasileira de Educação (1924-1931). Bragança Paulista: EDUSF, 1998.

. Quando a história da educação é a história da disciplina e da higienização das pessoas. In: FREITAS, Marcos Cezar (Org.). História social da infância no Brasil. São Paulo: Cortez, 1997. p. 269-287.

CAVALCANTI NETTO, João Uchôa. Lombroso ressuscitado. In: LOMBROSO, Cesare. O homem criminoso. Rio de Janeiro: Editora Rio, 1983. p. V-VI.

CHARTIER, Roger. O mundo como representação. Estudos Avançados, São Paulo, v. 5, n. 11, p. 173-191, abr. 1991

COUTO, Miguel. No Brasil só há um problema nacional: a educação do povo. Rio de Janeiro: Tipografia do Jornal do Comércio, 1927.

COUTO, Rita Cristina C. de Medeiros. Eugenia, loucura e condição feminina. Cadernos de Pesquisa, São Paulo, n. 90, p. 52-61, ago. 1994.

EDITORIAL. Educação Physica, Rio de Janeiro, n. 4, p. 11, mar. 1934.

FISHER. Irving. A nova educação physica. Educação Physica, Rio de Janeiro, n. 4, p. 13-14, mar. 1934

GINZBURG, Carlo. O queijo e os vermes: o cotidiano e as idéias de um moleiro perseguido pela inquisição. São Paulo: Companhia das Letras, 1987.

GOULD, Stephen Jay. A falsa medida do homem. São Paulo: Martins Fontes, 1999.

LEITE, Dante Moreira. $\mathbf{O}$ caráter nacional brasileiro: história de uma ideologia. São Paulo: Ática, 1992

LOBATO, Monteiro. Urupês. São Paulo: Editora Brasiliense, 1918.

LOMBROSO, Cesare. O homem criminoso. Rio de Janeiro: Editora Rio, 1983.

Movimento, Porto Alegre, v. 14, n. 01, p. 135-159, janeiro/abril de 2008. 
LOURENÇO FILHO. A pedagogia de Rui Barbosa. São Paulo: Melhoramentos, 1966.

MARQUES, Vera Regina Beltrão. A medicalização da raça: médicos, educadores e discurso eugênico. Campinas: Editora da UNICAMP, 1994.

NETTO, Americo R. Gymnastica e esporte: alguns critérios para differencial-os. Educação Physica, Rio de Janeiro, n. 16, p. 14-15, mar. 1938.

PRADO, Paulo. Retrato do Brasil: ensaio sobre a tristeza brasileira. São Paulo: Companhia das Letras, 1997.

SCHNEIDER, Omar. A revista Educação Physica (1930-1940): estratégias editoriais e prescrições educacionais. 2003. $342 \mathrm{f}$. Dissertação (Mestrado em Educação) - Programa de Estudos Pós-Graduados em Educação: História, Política, Sociedade, da Pontifícia Universidade Católica de São Paulo, São Paulo, 2003.

SCHNEIDER, Omar; FERREIRA NETO, Amarílio. Saúde e escolarização: representações, intelectuais, educação e educação física. In: OLIVEIRA, Marcus Aurélio Taborda de. Educação do corpo na escola brasileira. Campinas: Autores Associados, 2006. p. 111-133.

SHARMAN, Jackson R. A educação profissional dos professores de educação physica na Allemanha. Educação Physica, Rio de Janeiro, n. 19, p. 10-12 e 6970, jun. 1938.

WARDE, Mirian Jorge. Cultura e educação: o americanismo e a fabricação do homem: [Projeto de pesquisa]. Programa de Pós-Graduação em Educação da Pontifícia Universidade Católica de São Paulo, São Paulo, jun. 2001a.

Cultura e educação: o americanismo e a fabricação do homem. In: REUNIÃO DA EQUIPE DE PESQUISA “AMERICANISMO E EDUCAÇÃO”, 2001. Relatório... São Paulo: PUC, 2001b.

Americanismo e educação: um ensaio no espelho. São Paulo em Perspectiva, São Paulo, v. 14, n. 2, p. 37-43, abr./jun. 2000.

Movimento, Porto Alegre, v. 14, n. 01, p. 135-159, janeiro/abril de 2008. 